\title{
Principles in the management of chronic hepatitis B viral infection
}

\author{
Gerald Y Minuk MD FRCPC
}

GY Minuk. Principles in the management of chronic hepatitis B viral infection. Can J Gastroenterol 1999;13(1):75-77. Recently licensed and promising new experimental agents should have a profound impact on the treatment of patients with chronic hepatitis B virus (HBV) infection. However, certain management principles should remain unaltered. Recognizing the need for more urgent treatment in some individuals, being able to identify which patients require treatment and those who are most likely to respond to treatment, and selecting the optimal timing for treatment are clinical decisions that must continue to be addressed regardless of the antiviral agent 'of the month'. This review outlines general principles and provides a generic, timeless approach to the management of patients with chronic HBV infection.

Key Words: Antiviral therapy, Cirrhosis, Hepatitis B, Hepatocilic carcinoma, Liver disease

\section{Principes de la prise en charge d'une infection chronique au virus de l'hépatite $B$}

RÉSUMÉ : De nouveaux agents expérimentaux et prometteurs, qui ont récemment été approuvés pour leur mise en marché devraient avoir un impact profond sur le traitement des patients atteints d'une infection chron ique au virus de l'hépatite B (VHB). Cependant, certains principes de prise en charge ne doivent pas être modifiés. Le fait de reconnaître le besoin plus urgent de traitement chez certains sujets, de savoir identifier les patients qui nécessitent un traitement et ceux qui sont le plus susceptibles d'y répondre, et de choisir le meilleur moment pour traiter les patients, sont des décisions cliniques qui doivent rester pertinentes quel que soit « l'agent antiviral du mois ». Le présent article de synthèse met l'accent sur les principes généraux et propose une approche général iste et durable de la prise en charge des patients atteints d'une infection chronique au virus de l'hépatite B.
$\mathrm{H}$ epatitis B virus (HBV) is a 44-nanometre, doublestranded DNA virus that belongs to the hepadna family of viruses. Estimates suggest that approximately 300 million individuals are chronic HBV infection carriers worldwide. In Canada, the rate is between $0.1 \%$ and $0.2 \%$ of the general population; however, carrier rates 20 to 50 times that figure have been documented in the Canadian aboriginal community. The diagnosis of HBV infection is based on the presence of circulating hepatitis $B$ surface antigen ( $\mathrm{HBs} A g)$. The amount of viral replication can be estimated by the presence or absence of an envelope protein referred to as hepatitis $\mathrm{B}$ early antigen ( $\mathrm{HBeAg}$ ). Patients who are HBeAg-positive have high levels of viral replication, whereas patients who are $\mathrm{HBe} \mathrm{Ag}$-negative and antibody to $\mathrm{HBeAg}$ (anti-HBe) - positive generally have low levels of vi- ral replication. More quantitative measures of viral replicative activity and load can be provided by documentation of HBV-DNA levels in the circulation or from liver tissues. Antibodies to the hepatitis B core antigen (anti-HBc) reflect previous exposure to HBV. When the threshold for the anti-HBc assay is set at a high level, positive results indicate that exposure took place within the last three to six months. Because immunoglobulin M (IgM) anti-HBc levels also correlate with $\mathrm{HBV}$ replicative activity, setting lower threshold levels for IgM anti-HBc positivity allows this assay to be used as an additional marker of viral replication. The only 1 censed therapy for chronic HBV infection is recombinant alpha interferon, which is successful in converting an actively replicating virus to an inactive state ( $\mathrm{HBe}$ Ag to anti-HBe seroconversion) in approximately $40 \%$ of patients, with subse-

Liver Diseases Unit, Health Sciences Centre, Professor of Medicine and Pharmacology, University of Manitoba, Winnipeg, Manitoba

Correspondence and reprints: Dr GY Minuk, Liver Disease Unit, Health Sciences Centre, 820 Sherbrook Street, Winnipeg, Manitoba R3A 1R9. Telephone 204-787-4662,fax 204-775-4255, e-mail gminuk@cc.umanitoba.ca 
quent loss of $\mathrm{HBsAg}$ (evidence of ongoing infection) in 10\% to $15 \%$ of cases within five years of treatment. Numerous additional agents are in various stages of clinical trials and should become commercially available within the next two to five years. Thus, it is important and timely to review the general principles that apply to the treatment of patients with chronic hepatitis B infection.

\section{THE NEED FOR TREATMENT}

There are many reasons for treating and eradicating chronic HBV infection. The four most frequently cited include the following: to improve on the natural history of the disease; to alleviate symptoms; to decrease the risk of transmission; and to achieve cost savings for the health care system. The validity and relative strength of each indication warrants further discussion.

The natural history of chronic HBV infection depends largely on the age at which viral acquisition occurred. Approximately $90 \%$ to $95 \%$ of adult patients recover from acute HBV infection and develop long standing immunity (antiHBs positivity). In the majority of these cases, acute infection is subclinical, with the diagnosis made as a result of investigation for nonspecific fatigue and/or general malaise. An additional $1 \%$ to $2 \%$ of individuals develop fulminant hepatic failure, which often requires liver transplantation for survival. Antiviral therapy in this setting is unlikely to be of therapeutic benefit because the patients experience overly excessive rather than impaired eradication of $\mathrm{HBV}$ infection by the immune system. The remaining $5 \%$ to $10 \%$ of adult patients progress to chronic HBV infection over approximately 20 to 25 years. Of these chronic carriers, $20 \%$ to $30 \%$ develop cirrhosis and as many as $50 \%$ of patients with cirrhosis develop hepatocellular carcinoma. Morbidity and mortality rates in the latter group indicate that the need exists for effective antiviral therapy. The same concerns regarding morbidity and mortality are even more applicable to neonatal-acquired disease because $90 \%$ to $95 \%$ of infants progress to a chronic carrier state with only $5 \%$ to $10 \%$ recovering spontaneously and developing anti-HBs positivity. Fulminant hepatic failure is uncommon in neonatalacquired HBV infection because the immune system is not yet fully developed.

A relative paucity of data exists on the prevalence and severity of symptoms in patients with chronic HBV infection. In a recent study undertaken to provide such data about chronic hepatitis C carriers, $30 \mathrm{HBeAg}$-positive chronic HBV infection carriers were included as controls. Aside from reductions in mental health and general health perception, the remaining variables included in the Short Form 36 Quality of Life Questionnaire were similar to 17 healthy subjects with no evidence of liver disease. These findings warrant consideration of the adage, "it is difficult to improve on the asymptomatic patient."

With the advent of both passive and active immunoprophylaxis, it is no longer ethical to ascertain the risk of transmitting HBV from index cases to household contacts. However, in a recent study in which sera from susceptible
(anti-HBc negative) individuals residing in the same home as the index case were prospectively obtained every six months for a minimum of two years, only four of $96(5 \%)$ individuals developed serologic evidence of HBV infection. This figure was 10 times lower than the rate identified when the index case had an acute hepatitis A virus infection. Because effective immunoprophylaxis, and to a lesser extent public health counselling, were not available at the time of the study (1960 to 1962), these figures likely represent a reasonable approximation of the relative risk of HBV transmission within households, which appears to be quite low.

Employing a standard probability model consisting of 1000 chronic HBV infection carriers followed for 30 years, Dusheiko and Roberts reported a $25 \%$ and $37 \%$ savings in health care costs in patients with low and high probabilities of progression to end-stage liver disease, respectively, when treatment with an antiviral agent of $35 \%$ efficacy (HBe Ag to anti-HBe seroconversion) was compared with health care costs in the absence of treatment. Thus, significant cost savings would be realized by treating rather than observing patients with chronic hepatitis B infection who satisfy standard treatment criteria.

Although the need to treat chronic HBV infection on the basis of achieving improvement in symptoms and to decrease transmission rates is not particularly strong, the natural history of this disease and the financial savings associated with therapeutic intervention result in an overall need for pursuing antiviral therapy.

\section{WHO TO TREAT}

Proceeding on the premise that the need exists to treat patients with chronic HBV infection treatment ideally should be offered to patients who are at greatest risk of progressing to cirrhosis and/or hepatocellular carcinoma as well as to patients who are most likely to respond to antiviral therapy.

The standard for identifying patients who are most likely to progress to advanced disease is liver histology. Patients with chronic active hepatitis and/or bridging necrosis or fibrosis have a high rate of progression to cirrhosis, whereas the risk is much lower in patients with less active liver histology or nonspecific reactive changes. Of the various surrogate markers for histological activity, serum aminotransferases, and to a lesser extent IgM anti-HBc titres, have emerged as most informative. HBV-DNA levels on the other hand, are similar in patients with active versus inactive liver histology.

Data from treatments that largely augment the immune system such as interferon, as well as from studies monitoring specific antiviral agents such as adenine arabinoside and other nuceloside analogues, indicate that active liver histology and high aminotransferase values are useful positive predictor variables, whereas low HBV-DNA levels are less useful predictors. Conceptually, the success or failure of a therapeutic intervention in chronic HBV depends on whether that intervention alters the balance between viral target antigens and the immunological response to those an- 
tigens to a ratio that is favourable to the host. If so, the complete inhibition of viral replication and target antigen deposition that can be achieved with some of the new nucleoside analogues may interfere with the antigen-dependent immunological mechanisms inherent in interferon, vaccine and/or other immunological-enhancer based therapies.

\section{WHEN TO TREAT}

When to provide antiviral therapy depends largely on when the virus is acquired. In adults, it is prudent to wait six months following the onset of an acute HBV infection to determine whether the patient will develop a chronic carrier state (HBsAg-positive on two occasions a minimum of six months apart). Thereafter, the period during which progression to cirrhosis may occur, and therefore the period where treatment is most warranted, is largely defined by the period of active viral replication ( $\mathrm{HBe} \mathrm{Ag}$ and/or HBV-DNA positivity), which averages seven to 10 years. Thus, antiviral therapy need not be offered during the acute phase of the infection, when $90 \%$ to $95 \%$ of patients will spontaneously recover or once the patient has become $\mathrm{HBe} \mathrm{Ag}$-negative, when the risk of progression to cirrhosis has largely passed. In neonatalacquired disease, due to prolonged immune tolerance to the virus, active inflammatory disease and progression to cirrho-

\section{SUGGESTED READING}

Castiglia PT. Hepatitis in children. J Pediatr Health Care 1996;10:286-8.

Davis GL. Hepatitis B: diagnosis and treatment. South Med J 1997;90:866-70.

Dusheiko GM, Roberts JA. Treatment of chronic type B and C hepatitis with interferon alpha: an economic appraisal. Hepatology 1995;22:1863-73.

Lok AS, Lai CL, Wu PC, Leung EK, Lam TS. Spontaneous hepatitis Be antigen to antibody seroconversion and reversion in Chinese patients with chronic hepatit is B virus infection. Gastroenterology 1987;92:1839-43.

Minuk GY, Ding LX, Hannon C, Sekla L. The risks of transmission of acute hepatitis $\mathrm{A}$ and $\mathrm{B}$ virus infection in an urban centre. J Hepatol $1994: 21: 118-21$ sis do not typically occur until early adulthood, when liver enzyme abnormalities become apparent or more striking. If these abnormalities are extensive and persistent, the risk of progression to cirrhosis is sufficient to warrant antiviral therapy at the time these features are recognized. Whether adult or neonatal-acquired, antiviral therapy should not be offered when liver biochemical abnormalities or HBV-DNA levels (where available) are spontaneously changing. Such changes frequently reflect impending, spontaneous seroconversions to a $\mathrm{HBeAg}$-negative state and, therefore, obviate the need for antiviral therapy.

\section{CONCLUSIONS}

It is apparent that antiviral therapy in patients with chronic HBV infection is warranted on the basis of the natural history of the disease and cost savings analyses. However, because not all patients require treatment, those with features suggesting a high risk of progression (active histology, elevated aminotransferases and high anti-HBc levels) and a high probability of responding to treatment (active histology, elevated aminotransferases and low HBV-DNA values) should be targeted. Initiating antiviral therapy is most appropriate when the disease is clearly active but stable in severity.

Minuk GY, Ling N, Postl B, Waggoner JG, Nicolle LE, Hoofnagle JH. The changing epidemiology of hepatitis $\mathrm{B}$ virus infection in the Canadian north. Am J Epidemiol 1985;121:598-604.

Perrillo RP. Factors influencing response to interferon in chronic hepatitis B: implications for Asian and western populations. Hepatology 1990;12:1433-5.

Perrillo RP, Schiff ER, Davis GL, et al. A randomized, controlled trial of interferon alfa-2b alone and after prednisone withdrawal for the treatment of chronic hepatitis B. N Engl J Med 1990:323:295-301.

Zavaglia C, Mondazzi L, Maggi G, et al. Are alanine aminotransferase, hepatitis B virus DNA or IgM antibody to hepatitis B core antigen serum levels predictors of histological grading in chronic hepatitis $\mathrm{B}$ ? Liver 1997:17:83-7. 


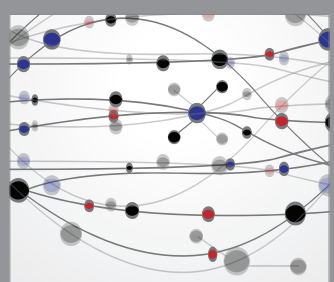

The Scientific World Journal
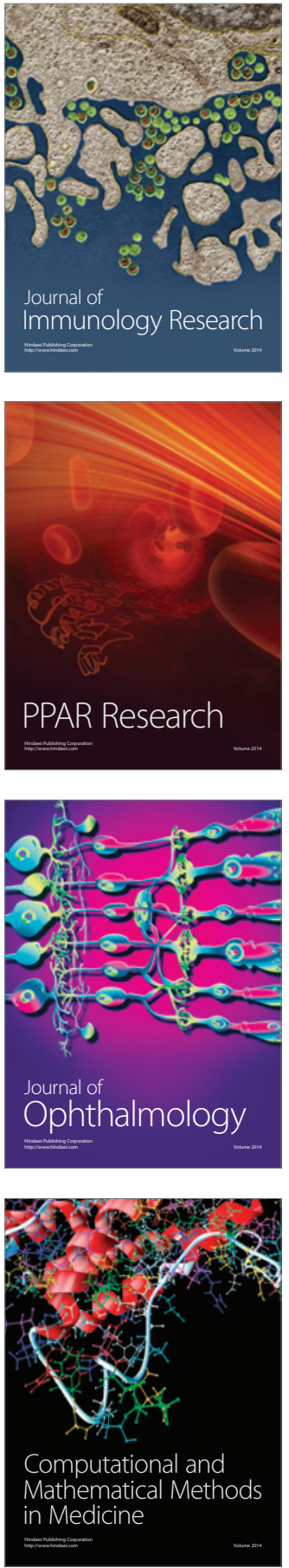

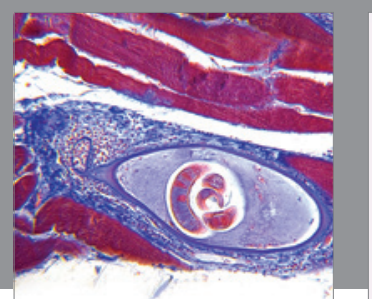

Gastroenterology Research and Practice

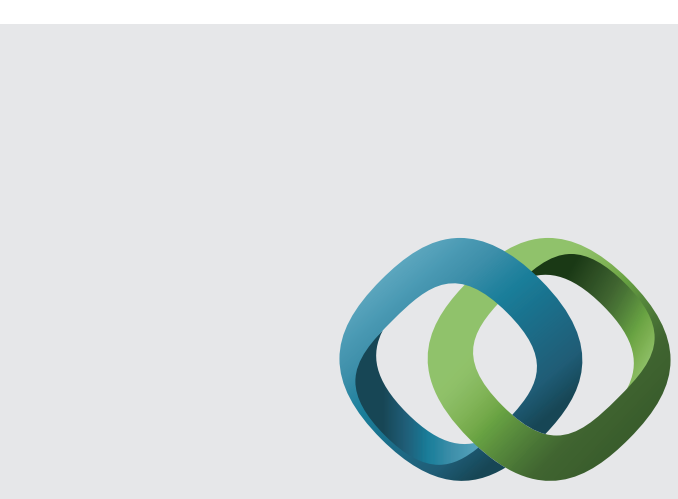

\section{Hindawi}

Submit your manuscripts at

http://www.hindawi.com
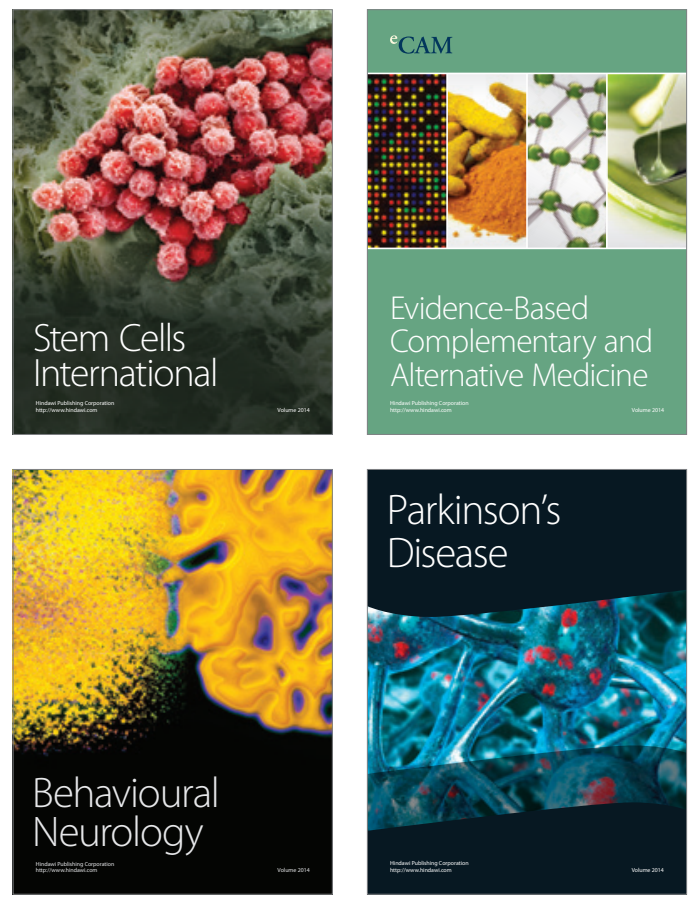
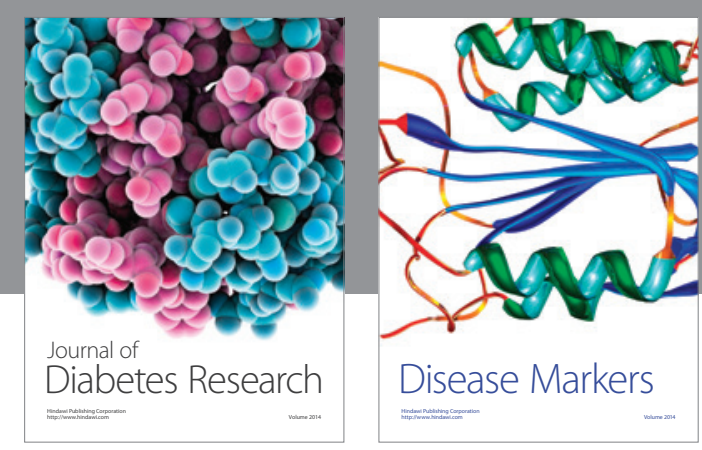

Disease Markers
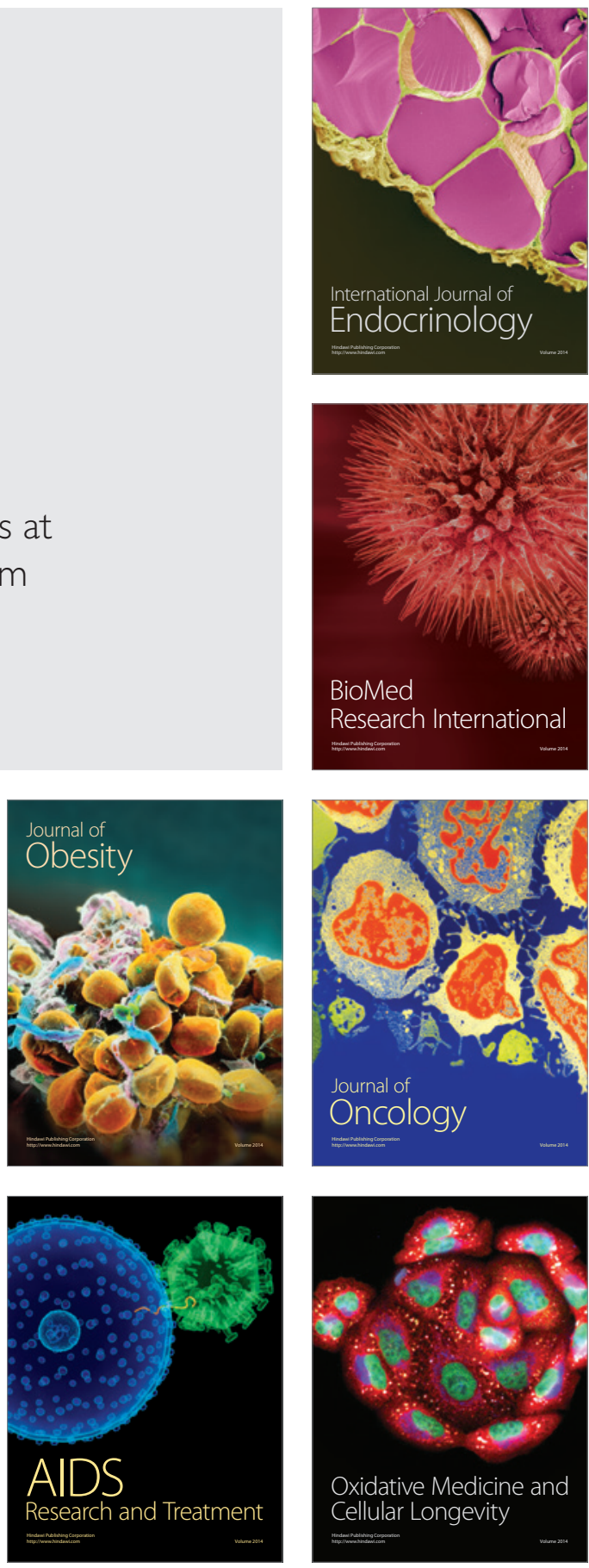